\title{
LA RIVALIDAD FESTERA. \\ Punto de encuentro y/o desencuentro entre comunidades
}

\author{
Miguel Ángel MARTÍNEZ POZO \\ Universidad de Jaén \\ mampozo@hotmail.com
}

RIVALRY IN THE FIELD. Popular festivities as a meeting point and/or disunity between communities

Resumen: Desde una metodología dialógica, este artículo parte de la base de la existencia de una rivalidad festera existente en numerosas poblaciones, ya sea dentro de una misma comunidad o entre comunidades. Lejos de dar soluciones, se propone simplemente como un ejercicio de reflexión donde se parte de diferentes aproximaciones teóricas planteadas en relación a la rivalidad, la envidia y el envidioso estableciéndose un diálogo entre los diferentes términos.

Abstract: This article, through a dialogic methodology, starts from the basis of the existence of a festive rivalry in numerous populations, either within the same community or between communities. It is not intended to provide solutions, but rather it is proposed as an exercise of reflection based on different theoretical approaches raised in relation to rivalry, envy and the envious person, establishing a dialogue between different terms.

Palabras clave: Rivalidad. Envidia. Fiestas. Comunidad. Identidad Rivalry. Envy. Popular Festivals. Community. Identity 


\section{Introducción}

$\mathrm{Si}$ analizamos detenidamente charlas en diferentes momentos de la vida cotidiana acerca de la violencia, existe un total acuerdo que esta debe erradicarse en pro de la paz. En cierta medida, es considerada inhumana, ajena a nuestra propia naturaleza pero, en cambio, las situaciones violentas y, cómo no, las rivalidades, son un fenómeno constante y, en ningún momento, una excepción. Es así cómo esta, como parte de un ritual perenne, se encuentra en innumerables situaciones cotidianas (relaciones, familia, trabajo, etc.) y en la propia fiesta existiendo, no solo como parte entre habitantes de una misma comunidad sino también, como punto de encuentro y/o desencuentro entre comunidades vecinas y hermanas.

Si retrocedemos nuestra mirada al pasado, multitud de festividades surgen como disputa y rivalidad entre poblaciones cercanas y, en su mayoría, sustentadas en un motivo religioso o civil. Aunque originariamente el fundamento de estas relaciones antagónicas pudiera derivar de lo expresado, a día de hoy, cobra mayor importancia el sentimiento identitario unido al afán político de ser turísticamente el más valorado en una determinada fecha o entre iguales (Martínez, 2017a).

\section{La rivalidad festiva}

Alrededor de esos específicos y concretos días tan esperados por toda una comunidad en torno a una fiesta, existe una enrevesada estructura donde convergen elementos y complejidades sociales de primer orden siendo, una de ellas, la rivalidad (Martínez Pozo, 2015: 312).

"Una rivalidad es siempre una suma de detalles que considerados por separado son nimios y hasta irrelevantes. Una rivalidad es a lo sumo una manera de alumbrar los hechos siempre desde la misma mirada: el duelo. Una rivalidad

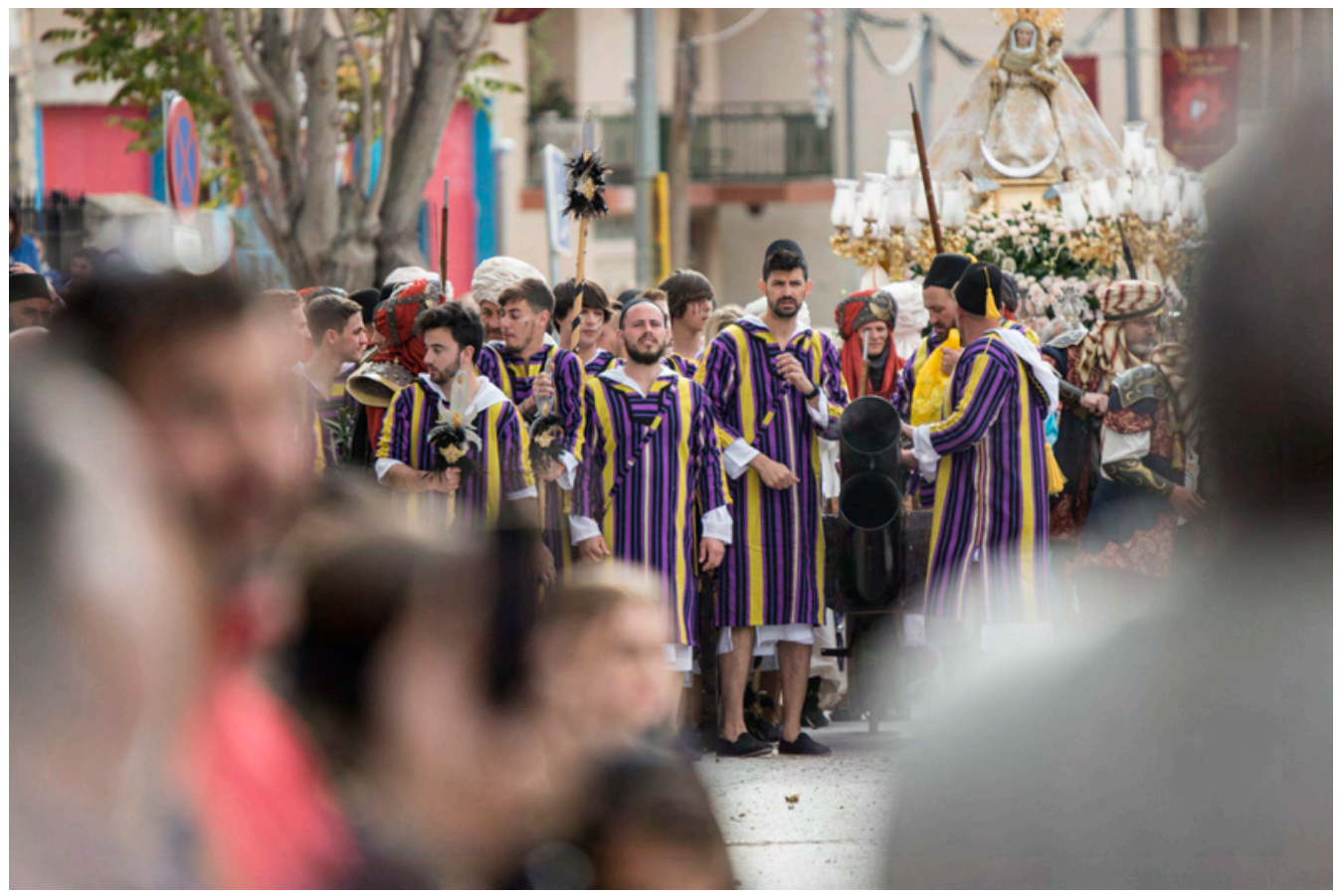

Foto 1. Fiestas de moros y cristianos de Benamaurel. La batalla (Granada) Fotografía de Alejandro Pérez Herrero. 


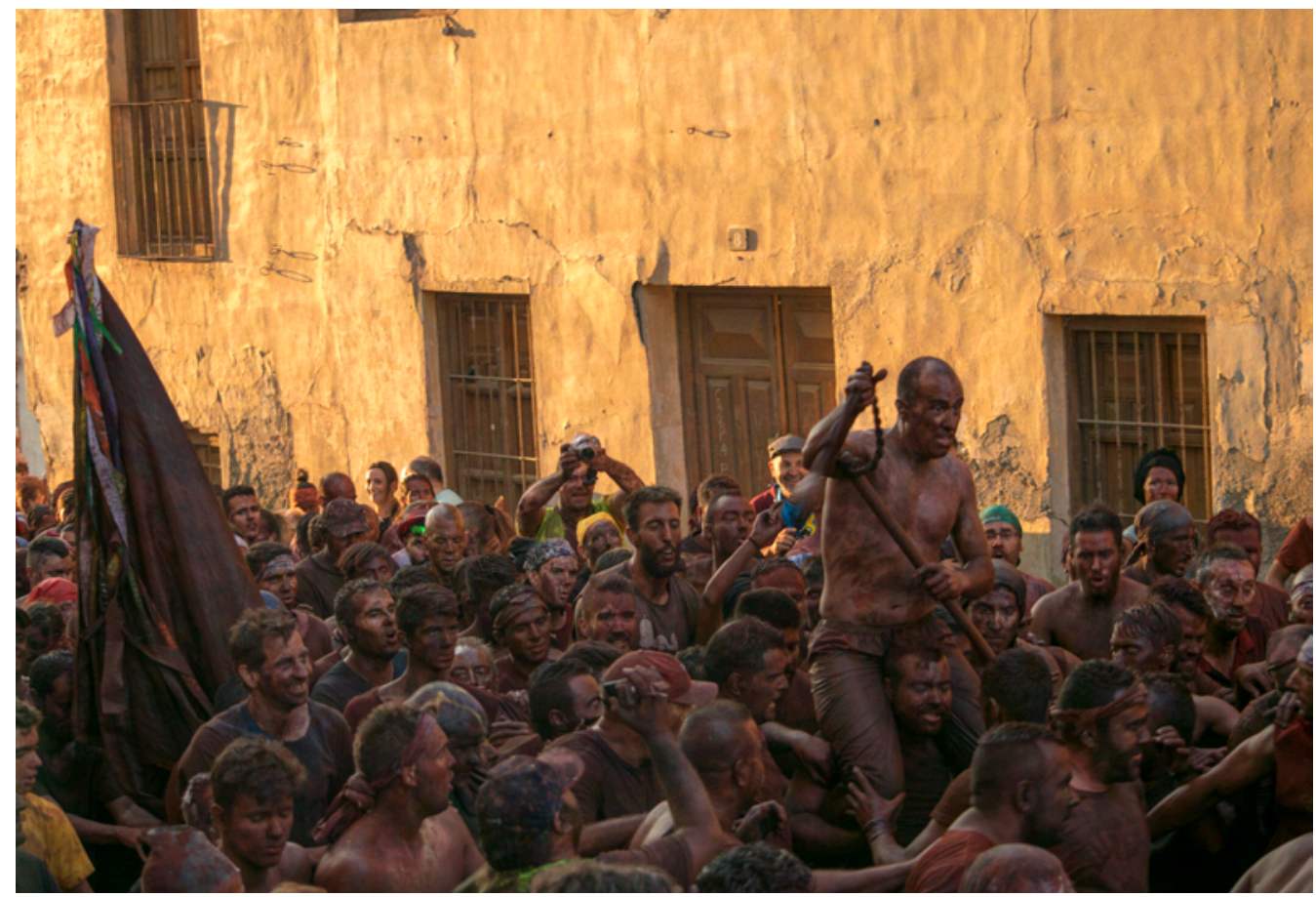

Foto 2. Cascamorras en Guadix(Granada). Fiesta de Interés Turístico Internacional. Fotografía Pilar Molero.

como lo señala la etimología latina tiene que ver con el concepto de río que une y separa al mismo tiempo. En este sentido, el rival es aquel que transitaba por el río o vivía a orillas de él. Es a la vez el de enfrente, el propio vecino cuya cercanía no es bienvenida y motivo de suspicacia, desprecio, codicia, envidia, odio o rechazo. El juego de lenguaje de la rivalidad despierta conexiones y establece puentes semánticos $\mathrm{y}$, sin duda, pragmáticos entre nociones como conflicto, duelo, antagonismo, competencia, emulación, diferendo, disputa, enfrentamiento, riña, gresca, reyerta, entre otras. También el lenguaje de la rivalidad abarca la idea de violencia verbal y simbólica o física y conativa" (Schaffhaurser Mizzi, 2013: 160-161).

Las rivalidades entre comunidades y/o poblaciones, suelen derivar por conflictos históricos creados, especialmente, por riegos, por linderos, por poderes político-religioso-industrial desdibujando todas sus relaciones de cercanía y complementariedad que, desde siempre habían existido por cuestiones familiares comunes, comercio, entre otras. Freud trató este distanciamiento, tal y como hemos dicho anteriormente, como "un narcisismo de las pequeñas diferencias"(Freud, 1978: 55-56) o Sáenz, M. nos describe como la conversión, por parte de sus habitantes, de esa identidad local como su "patria chica"(Sáenz, 1939: 113). Está claramente constatado que, en situación de rivalidad, la identidad del uno y del otro se ensimisma en un círculo vicioso o se reflecta en un espejo donde el rival es uno mismo (Girard, 1963).

"De entrada se entendería que la pseudoviolencia festiva se comporta a la manera de un termostato que sostiene a un nivel aceptable las tensiones derivadas de la coacción a que la sociedad somete a sus componentes, obligándoles a convivir" (Delgado, 2008: 85). 
A su vez, en cualquier población donde nos situemos, nos encontraremos latente una rivalidad político-religiosa por controlar la fiesta. El Ayuntamiento, que intentará reconducir la fiesta de acuerdo a sus intereses, y la Iglesia, que se comunicará a través de las Hermandades con el pueblo siempre que la fiesta se sustente en un patrón o patrona. Entre ambas, en algunos casos de festividades, existirán diferentes Asociaciones locales que serán las verdaderas intermediadoras. Por consiguiente, dentro de una sociedad supuestamente homogénea, nos encontraremos con ambigüedades y conflictos entre ambas instituciones e incluso internamente entre ellas. Es así cómo, la propia fiesta:

"Cumple una función mediadora con vistas a la integración del sistema social, la integración de los individuos en el sistema y consigo mismos, la integración de la sociedad en el ecosistema natural y con el ámbito de lo divino o del sentido atribuido a la globalidad de la experiencia del mundo. En el fondo, siempre pone en juego alguna forma de poder, referida a un marco de decisiones colectivas. Administra la legitimación del poder por una última instancia simbolizada, mediante el logro de la adhesión vivida a un sistema de ideas y valores compartido. En cierto modo, los participantes andan siempre negociando con el poder, sea para servirse de él o para servirlo, y frecuentemente de manera ambigua. Se instaura una dialógica entre el poder, que se sacraliza, y lo sagrado que se imbuye de poder" (Gómez, 2002: 18).

A esto hay que sumar las rivalidades locales internas promovidas, principalmente, por intereses económicos, donde la población se dividirá entre aquellos que desean la fiesta en el casco urbano, ya que poseen negocios que serán beneficiados, y aquellos que, optando

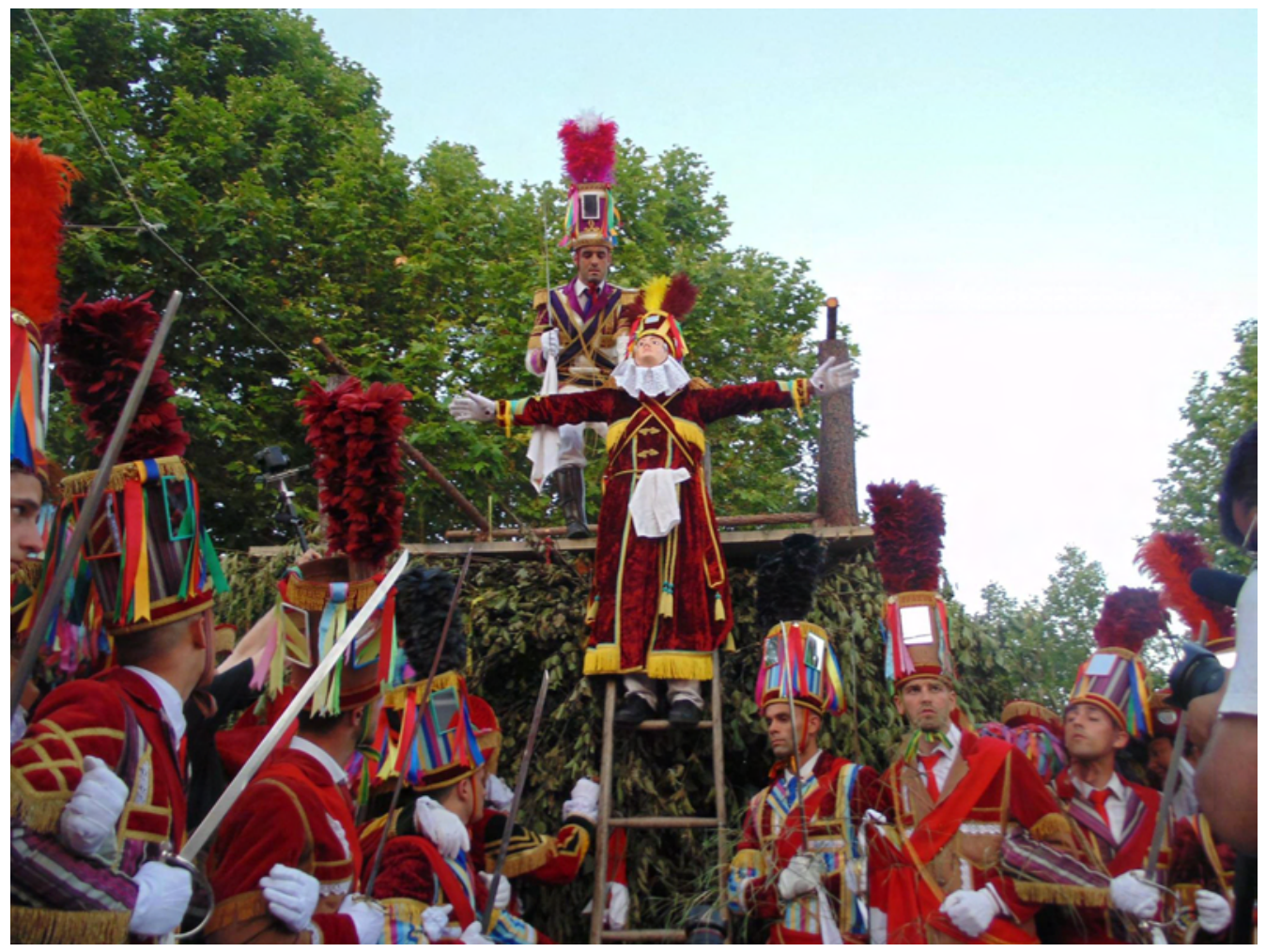

Foto 3. Bugios e mourisqueiros en Sobrado(Portugal). Foto Bárbara Lito. 
por la tranquilidad y descanso fundamentalmente nocturno, la prefieren en un recinto ferial en la periferia. Nos encontramos pues con la divergencia sobre el uso del espacio público, privado o común y su utilización (Delgado, 2007). Y todo esto sustentado en las diferentes discusiones familiares o entre amigos fruto de las visiones opuestas alrededor de los diferentes rituales, actos o momentos festivos.

Pero la rivalidad festiva, aunque parezca banal, aun estando en pleno siglo XXI, esta se acentuará en poblaciones donde sus habitantes más puristas (Martínez, 2017b: 247-263), con el fin de no romper sus esquemas asentados tradicionalmente, impiden o se niegan a la incorporación de nuevos actos, elementos o a la aportación de nuevos conocimientos y documentación producto de investigaciones realizadas o de las transformaciones de la fiesta acorde a la evolución de las propias sociedades.

Pero no solo es esto, tratando la rivalidad no solo dentro de una comunidad sino también entre comunidades, Espinoza, en su Tratado de Ética expone lo siguiente:

"Por el sólo hecho de imaginar que alguien goza de una cosa amaremos esa cosa y desearemos gozar de ella. Ahora bien, imaginamos que se opone a esta alegría el hecho de que él goce esa misma cosa; por consiguiente nos esforzaremos para que no lo posea" (Espinoza, 1980: 199).

Esto supone, no solo un impedimento psicológico muy serio entre quienes la poseen, sino también una fuente de sufrimiento innecesaria, de frustración o de mortificación narcisista recurriendo, en muchos casos, a la falta de respeto, desprestigio o a la injuria al prójimo como último recurso a utilizar. Pero aun más grave, este individuo o colectivo puede llegar a fantasear o desear abiertamente que aquellas personas promotoras del cambio "sufran un daño físico e incluso la muerte"( Castilla del Pino, 2009) para poder dar fin a sus males "encubriéndose tras él/ellos de modo cínico un odio tremendo, el cual, inconscientemente, va encaminado a tratar de perjudicar al otro"(Raimundo, 2004: 60). Podríamos decir que en este momento, la rivalidad festiva se convierte en una envidia ajena.

\section{La envidia como parte de la fiesta}

"La envidia es maladaptativa porque estropea y, en ocasiones, anula completamente el placer de la admiración, el gozo de la amistad, la utilidad del compañerismo y la solidaridad, el júbilo por los logros de otros, la contemplación de la belleza, de la habilidad y del ingenio y, también a veces, el simple deseo de emular al mejor"(Paniagua,2002: 35-42).

Pero esta envidia, pecado capital e infructuoso sentimiento, suele corromper, amargar y destruir al ser humano o al colectivo que lo posee pero, en cambio, la negarán como acto defensivo. Convertida en una rivalidad destructiva, esta suele oscilar siempre entre el folclore y posturas identitarias en búsqueda de la diferenciación, del separatismo o de la búsqueda de una insignificancia alrededor de grandes similitudes o semejanzas. Así pues nos encontramos con que la fiesta:

"Representa la alteridad y, así, se parte de un núcleo de ideas que tienen apariencia de reales, ser parte de un nosotros único y exclusivo, enfrentado a los otros, aunque sean siempre parte de ese nosotros porque, en última instancia, lo que enseña, paradójicamente, a cualquiera [...] es que en ese nosotros siempre hay una parte de los otros" (Anta Félez, 2003: 72). 


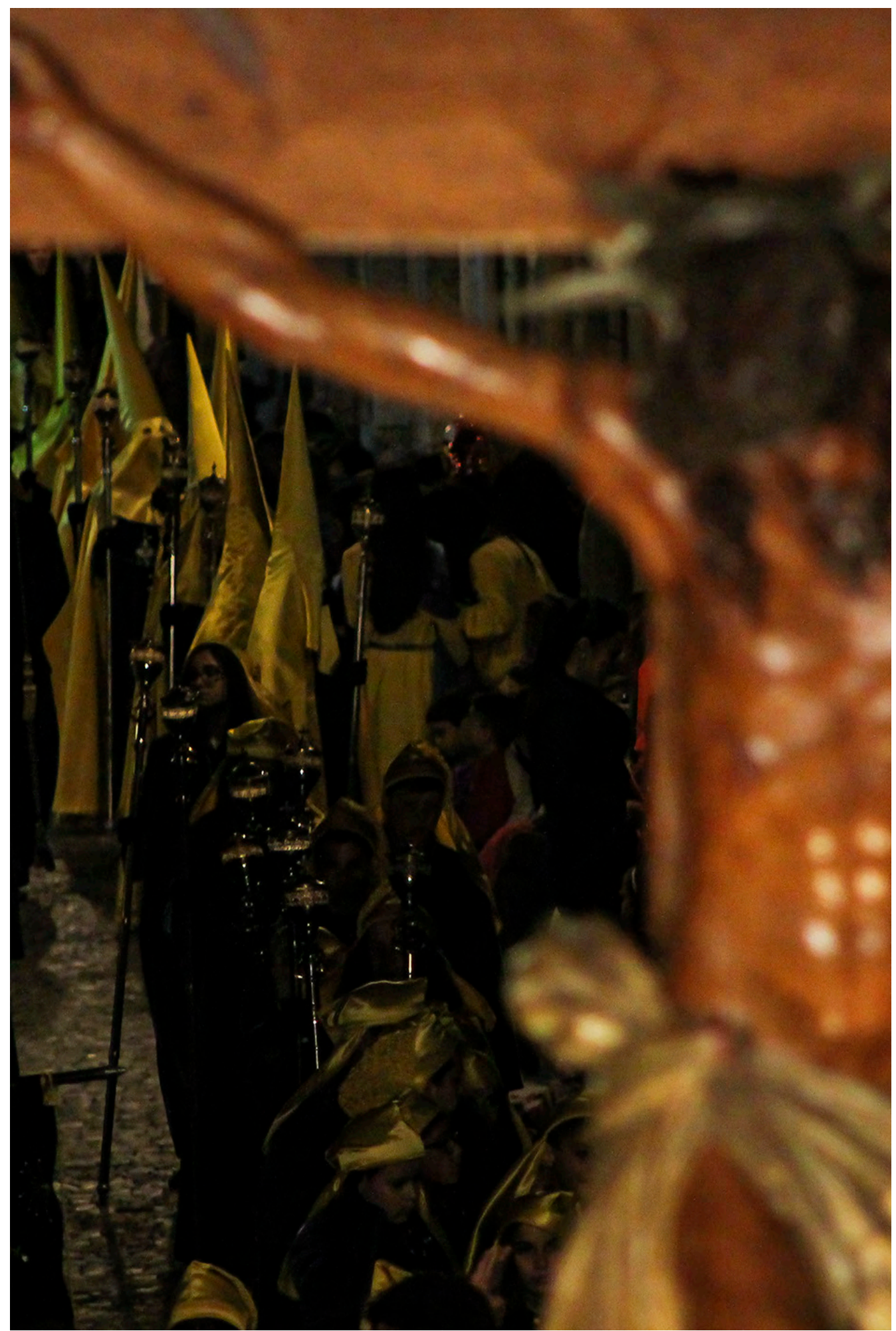

Foto 4. Semana Santa de Cieza (Murcia). Fotografía Manuel Albendín Valenzuela. 
El envidioso, tratado desde el individualismo o desde una comunidad en su conjunto, sufre en su propia soledad pero siempre teniendo presente al envidiado; siente dentro pero necesita indudablemente exteriorizarlo para intentar convertirlo en una construcción social; mi envidia no es personal, es de una comunidad. Así pues, convierten sus vivencias en unidades de acción cargadas de significados compartidos, fuertemente estereotipadas, dentro de contextos ritualizados.

En la actualidad, las redes sociales son utilizadas, en muchos casos, para desprestigiar, infravalorar, calumniar, humillar e incluso como búsqueda de conflictos fruto, bien de un sector poblacional o personas específicas que, amparándose en el Artículo 20 de la Constitución Española, pero obviando los límites expresados en el punto 4 de dicho artículo, alientan con sus palabras al odio, a rencores y enfrentamientos innecesarios bien por falta de argumentos a sus ideales, los cuales han sido modificados producto de innovaciones, $\mathrm{o}$ bien por el propio devenir la historia. Pero su fin es desgastar el rol ventajoso del envidiado, ya que así, el envidioso ve su propio valor comparativamente rehabilitado. Es, en este contexto, donde el envidioso no es un sujeto aislado; es un actor.

"Eso nos obliga a ser buenos actores, pero también diestros descifradores de las sutilezas de la interpretación de los demás. El modelo escenográfico nos permite enfatizar el carácter social y simbólico de la envidia. "Ser" envidioso es más que sentir envidia: es quedar emplazado, en cierto modo atrapado, en una determinada dramaturgia, ocupar un lugar concreto en ella y actuarlo según las opciones de los papeles correspondientes. En cierto modo, somos envidiosos antes de sentir envidia, dada la correlación de fuerzas y valores en la que nos encontramos inmersos [...] La envidia es un relato que, culmine o no sus metas, va de la frustración al sueño de empoderamiento, del desposeimiento a la aspiración, del fracaso a la esperanza" (López, 2016: 1-24).

Hemos de decir que, la postmodernidad, dentro de sus peculiaridades y características, debido a la facilidad de extender tu pensamiento fruto de la libertad existente convertida en un libertinaje sin control en ciertas ocasiones, el rival, ha creado una nueva personalidad que podríamos llamarla heroica, donde el sufrimiento e incluso el acoso a través de los medios de comunicación (especialmente de las redes sociales), han doblegado a la entereza moral. En cambio, tal y como nos argumenta Korstanje, M., en la mayoría de los casos "ser víctima pone al damnificado por encima de otros[...] La calidad de víctima pone a la persona por encima de otras, le confiere mayor legitimidad sobre otros"(Korstanje, 2015: 31-49). Así, hablar del otro, supone importarte más de lo que creías.

En cambio, las rivalidades que puedan existir entre poblaciones debe ser difuminada por las instituciones que rigen la fiesta: "en este sentido los políticos de ambos municipios tienen un papel muy importante ya sea para enfatizar o relativizar todo aquello que motiva o permite la diferenciación social entre ambas poblaciones" (Shaffhaurser Mizzi, 2013: 160-161).

\section{Conclusiones}

A pesar de todo ello y, desde nuestra propia visión personal, la fiesta, tiene la virtud de poner la comunidad por encima de la gente (Turner, 1988). Y no podemos considerarlo ser hipócritas durante un determinado tiempo (los días festivos), sino la vivencia y pertenencia a una tradición, a una identidad local donde los elementos negativos existentes entre las personas, alrededor de la fiesta, se disuelven o pasan a un segundo plano en torno a su pueblo, su legado y su tradición. El sentimiento de lo común compartido, con la fiesta, es reactivado reafirmando, la identidad diferenciadora frente a la compartida pero, a la misma 
vez, dentro de esta identificación local (lo nuestro como pueblo) se encuentra, por un lado, una identificación colectiva (nuestras fiestas) como señal de zona geográfica o como lazo de unión con otras poblaciones. Porque, aunque exista una cierta rivalidad entre poblaciones cercanas, vecinos o instituciones, la fiesta suele cumplir una función sociológica en la que se refuerza las estructuras sociales, se regulan las tensiones entre comunión y separación y se comparten valores por encima de los que ellos mismos creen. Construye lazos de unión y contribuye a un acercamiento poblacional (Martínez Pozo, 2015: 312-313).

$\mathrm{Y}$, aunque "para algunos la propia felicidad es inversamente proporcional a la de los otros"(Hernández, 2013: 17-21) la rivalidad puede convertirse en felicidad siempre que esta sea compartida y plural donde las comunidades miren con un mismo objetivo: el bien común.

\section{Bibliografía}

ANTA FÉLEZ, J.-L. (2003). "Violencia, comunidad y complejidad: moros y cristianos en Carchelejo (Jaén)" en ALBERT-LLORCA, M. y GONZÁLEZ ALCANTUD, J.A.: Moros y cristianos. Centro de Investigaciones Etnológicas “Ángel Ganivet”. Diputación Provincial de Granada. Granada.

CASTILLO DEL PINO, C. (2000). Teoría de los sentimientos. Tusquets. Barcelona, 2000.

DELGADO, M. (2007). "El espacio público como ideología” en Jornadas Marx siglo XXI, Universidad de la Rioja. Diciembre de 2007. Logroño. pp. 1-13.

DELGADO, M. (2008). "Tiempo e identidad. La representación festiva de la comunidad y sus ritmos" en Jornadas de reflexión en la ciudad festiva. II Jornadas de Antropología y religión. Zainak. Bilbao, 26.

ESPINOZA, B. (1980). Ética demostrada según el orden geométrico. Ed. Orbis. Madrid.

FREUD, S. (1978). Malestar en la cultura. Alianza Editorial. Madrid.

GIRARD, R. (1963). Le bouc émissaire. Grasset. París.

GÓMEZ GARCÍA, P. (2002). "El ritual como forma de adoctrinamiento" en Gazeta de Antropología, $\mathrm{n}^{\mathrm{o}} 18$.

HERNÁNDEZ, SALAZAR, P. (2013). "Felicidad en plural. Del individuo a la relación" en UIC. Foro Multidisciplinario. Enero-marzo. pp. 17-21.

KORSTANJE, M. (2015). "Postmodernidad y personalidad heroica, cuando el sufrimiento es placentero" en Pensamiento americano, vol. 8, $n^{\circ}$ 14. Enero-Junio. pp. 31-49.

MARTÍNEZ POZO, M.A. (2015). Moros y cristianos en el mediterráneo español. Antropología, educación, historia y valores. Ed. Gami. Granada.

MARTÍNEZ POZO, M.A. (2017a). "Fiestas de moros y cristianos en España. Búsqueda de valores contemporáneos" en Actas del I Congreso Internacional y IV Congreso Nacional de Moros y Cristianos. Universidad de Alicante. Alicante. pp. 247-263.

MARTÍNEZ POZO, M.A. (2017b). Cascamorras. Antropología, historia, leyenda, tradición y valores. Ed. Gami. Granada.

PANIAGUA, C. (2002). Psicología de la envidia en Ars Médica. Revista de Humanidades Médicas.

RAIMUNDO GUERRA CID, L. (2004). Tratado de la insoportabilidad. La envidia y otras virtudes humanas. Crecimiento Personal. Colección Serendipint. Editorial Desclée de Brouwer, S. A. Sevilla.

SÁENZ, M. (1939). México íntegro. Fondo de Cultura Económica. México.

SCHAFFHAURSER MIZZI, P. (2013). "Las distancias de la cercanía. Una aproximación a la rivalidad regional entre Sahuayo y Jiquilpan, Michoacán" en Relaciones. Estudios de historia y sociedad, vol. XXXIV, $\mathrm{n}^{\circ} 135$. p. 160-161.

TURNER, V. (1988). El proceso ritual: estructural y antiestructura. Taurus. Madrid.

\section{3}

